\title{
SPECTRUM OF HEPATITIS C VIRUS (HCV) GENOTYPES AMONG DIAGNOSED CASES OF HCV IN RAWALPINDIAND ISLAMABAD REGION OVER THE PERIOD OF SIX YEARS
}

\author{
Hamna Javed', Tehreem Arif', Saba Arshad', Saadia Khan'Baloch, Bushra Anwar², Muhammad Aleem \\ Khan $^{3}$ and Muhammad Faheem Shahzad ${ }^{3}$
}

\author{
${ }^{1}$ Rawalpindi Medical College, Rawalpindi \\ ${ }^{2}$ Health Services Academy, Islamabad \\ ${ }^{3}$ Department of Nuclear Medicine, Nuclear Medicine, Oncology \& radiotherapy Institute (NORI), Islamabad \\ Correspondence: Muhammad Aleem Khan.Email:draleemkhan@yahoo.com
}

\begin{abstract}
Background: Determination of an individual's HCV genotypes prior to antiviral therapy has become increasingly important for the deciding clinical management and predicting prognosis of HCV infection. Relative genotype proportions are needed to inform to healthcare models, which should be geographically tailored. To our knowledge, there are no studies reporting genotype pattern in Rawalpindi/lslamabad region.We aimed to determine the frequency of different genotypes in HCV positive cases in the population of Rawalpindi/ Islamabad over the period of five years.

Methods: Data of total of three thousand eight hundred and eighteen $(n=3818)$ HCV positive adult of both genders were screened for genotype testing over the period of six years were analyzed.

Results: Most frequent genotype identified in our study was genotype 3, accounting for $95.8 \%(n=3657)$ of HCV positive cases. The second most common genotype was Type 1 accounting for $2.9 \%(n=109)$ of HCV positive cases. Other genotypes were Type $2(0.3 \%, n=12)$ and Type $4(0.1 \%, n=5)$. Mixed genotype (Type 1 and 3 ) were detected in almost $1 \%(n=35)$ of cases. We did not find genotype 5 and 6 in our study sample. No significant difference was observed among males and females in genotype distribution $(P>0.05)$.

Conclusion: The most common genotype among HCV patients were found to be genotype 3 followed by genotype 1 as the second most common in Rawalpindi/lslamabad region during the study period.

Keywords: HCV, HCV genotype; interferon therapy, Viral Infection

\section{Introduction:}

Hepatitis C virus (HCV) is a globally prevalent pathogen and one of the major causes of mortality and morbidity especially in developing countries like Pakistan.[1,2] Recent estimates revealed an increase in its seroprevalence over the last $10-15$ years to $2.8 \%$, corresponding to $>185$ million infections worldwide.[3] Prevalence of $\mathrm{HCV}$ infections in Pakistani population has been estimated to be $8 \%$ and is increasing day-by-day.[4,5] HCV has been classified into 1-6 major genotypes on the basis of phylogenetic analysis of nucleotide sequences.[6] HCV genotypes have different biological properties, clinical outcome and response to antiviral treatment. Study of genotyping pattern provides important clues about transmission and pathogenesis as well as contributes to the development of an effective preventive and curative strategy. [7] HCV genotypes and subtypes have variable distribution around the globe. Predominant genotypes in the United States and Europe are $1 \mathrm{a}$ and $1 \mathrm{~b}$ respectively.[8,9] HCV genotype 2 is more prevalent in countries of West Africa[10] while genotype $3 a$ is more frequently found

in Australia and South Asia.[11] Moreover, genotypes 4,5 and 6 are frequently found in Central Africa, South Africa and Asia.[12] All these HCV genotypes show $31-34 \%$ heterogeneity in their nucleotide sequences and approximately $30 \%$ heterogeneity in their amino acid sequences.[13]Although genotype 3 is reported as most prevalent form in Pakistan, yet, studies have shown regional variations in the prevalence of different genotypes. Other genotypes were also present in the patients infected with $\mathrm{HCV}$, but were of lesser frequency. [14,15] Determination of an individual's HCV genotypes prior to antiviral therapy has become increasingly important for the deciding clinical management and predicting prognosis of HCV infection. It is the strongest predictive parameter for sustained virological response (SVR).[16] Patients with different $\mathrm{HCV}$ genotypes respond differently to antiviral therapy and characterization of these genetic groups may facilitate and contribute to the development of an effective vaccine against infection with HCV. Relative genotype proportions are needed to inform to healthcare models, which should be geographically tailored. To our knowledge, there are
\end{abstract}


no studies reporting genotype pattern in Rawalpindi/lslamabad region. This study was designed with intent to assess the genotype pattern of $\mathrm{HCV}$ in our region in order to provide inputs towards developing effective preventive and curative strategy against this infection. HCV is becoming a growing public health concern in Pakistan and knowing its genotyping pattern in our population will aid in developing effective vaccines against most common types.

\section{Methodology}

It was a retrospective cross-sectional study carried out at Nuclear Medicine, Oncology and Radiotherapy Institute (NORI), Islamabad, Pakistan. The study was observational in nature and all diagnosed cases of HCV infection referred for genotpye testing on routine basis were included (non-probability purposive sampling). Results of individual patient were duly informed and consent was taken for enrollment for analysis of consolidated results. We did not use any sample size calculation formula or pilot study to calculate the sample size. Data collected over a period of six years (Jan 2010 to December 2015) were analyzed. Study design was approved by the hospital ethical committee. HCV RNA was extracted and reverse transcribed to synthesis CDNA that was further subjected to nested PCR for detection of HCV viral RNA. The multiplex PCR genotyping for HCV was done only for the samples with detected HCVRNA.

\section{Results:}

A total of three thousand eight hundred and eighteen $(n=3818)$ HCV positive adults of both genders were screened for genotype testing during the period. Age and gender distribution in the study sample is summarized in table 1. Most frequent genotype identified in our study was genotype 3 , accounting for $95.8 \%(n=3657)$ of HCV positive cases. The second most common genotype was Type 1 accounting for $2.9 \% \quad(n=109)$ of HCV positive cases. Other genotypes were Type $2(0.3 \%, n=12)$ and Type 4 $(0.1 \%, n=5)$. Mixed genotype (Type 1 and 3$)$ were detected in almost $1 \%(n=35)$ of cases. We did not find genotype 5 and 6 in our study sample. No significant difference was observed among males and females in genotype distribution $(P>0.05)$. Results are summarized in table 2 and 3 .

Table 1: Age and sex distribution

\begin{tabular}{|l|c|c|c|}
\hline GENDER & $\mathbf{n}$ & $\begin{array}{c}\text { MEAN AGE } \\
\text { (YEARS) }\end{array}$ & $\begin{array}{c}\text { STD. } \\
\text { DEVIATION }\end{array}$ \\
\hline MALES & $\begin{array}{c}1732 \\
(45.4 \%)\end{array}$ & 39.6 & 12.2 \\
FEMALES & $\begin{array}{c}2086 \\
(54.6 \%)\end{array}$ & 41.1 & 10.7 \\
TOTAL & $\begin{array}{c}3818 \\
(100 \%)\end{array}$ & 40.4 & 11.4 \\
\hline
\end{tabular}

Table 2: Frequency of genotype in study sample

\begin{tabular}{|c|c|c|}
\hline $\begin{array}{c}\text { HCV } \\
\text { GENOTYPE }\end{array}$ & FREQUENCY & PERCENT \\
\hline TYPE 1 & 109 & 2.9 \\
TYPE 2 & 12 & 0.3 \\
TYPE 3 & 3657 & 95.8 \\
TYPE 4 & 5 & 0.1 \\
MIXED TYPE 1 AND & 35 & 0.9 \\
3 \\
TOTAL & 3818 & 100.0 \\
\hline
\end{tabular}

Table 3: Gender Based stratification

\begin{tabular}{|c|c|c|c|c|}
\hline \multirow[b]{2}{*}{$\begin{array}{c}\text { HCV } \\
\text { GENOTYPE }\end{array}$} & \multicolumn{2}{|c|}{ GENDER } & \multirow[b]{2}{*}{ TOTAL } & \multirow{2}{*}{$\begin{array}{c}P- \\
\text { VALUE } \\
\text { CHI- } \\
\text { SQUARE }\end{array}$} \\
\hline & MALES & $\begin{array}{c}\text { FEMALE } \\
\mathrm{S}\end{array}$ & & \\
\hline \multirow{2}{*}{ TYPE 1} & 59 & 50 & 109 & \multirow{12}{*}{0.464} \\
\hline & $54.1 \%$ & $45.9 \%$ & $100.0 \%$ & \\
\hline \multirow{2}{*}{ TYPE 2} & 5 & 7 & 12 & \\
\hline & $41.7 \%$ & $58.3 \%$ & $100.0 \%$ & \\
\hline \multirow{2}{*}{ TYPE 3} & 1650 & 2007 & 3657 & \\
\hline & $45.1 \%$ & $54.9 \%$ & $100.0 \%$ & \\
\hline \multirow{2}{*}{ TYPE 4} & 2 & 3 & 5 & \\
\hline & $40.0 \%$ & $60.0 \%$ & $100.0 \%$ & \\
\hline \multirow{2}{*}{$\begin{array}{c}\text { MIXED TYPE } 1 \\
\text { AND } 3\end{array}$} & 16 & 19 & 35 & \\
\hline & $45.7 \%$ & $54.3 \%$ & $100.0 \%$ & \\
\hline \multirow{2}{*}{ TOTAL } & 1732 & 2086 & 3818 & \\
\hline & $45.4 \%$ & $54.6 \%$ & $100.0 \%$ & \\
\hline
\end{tabular}

\section{Discussion}

HCV reported to exhibit high genetic diversity, characterized by regional variations in genotype prevalence. This poses a challenge to the improved development of vaccines and pan-genotypic treatments, which require the consideration of global trends in HCV genotype prevalence. Situation in Pakistan is even worse where published data is scarce and most data are based on relatively smaller sample size leaving a big question mark for the significance of the results published by these authors. It has been reported that Pakistan seems to have high prevalence of hepatitis $C$ virus type 3.[17] About 10 million Pakistani population is infected with Hepatitis $\mathrm{C}$ virus (HCV). The prevalence is even more pronounced among high risk population.[18] In this study, we gathered dataover the period of six years and a total of three thousand eight hundred and eighteen ( $n=3818)$ HCV positive adult of both genders were screened for genotype testing during this period. Our results showed that Most frequent genotype identified in our study was genotype 3 , accounting for 
95.8\% ( $n=3657)$ of HCV positive cases. The second most common genotype was Type 1 accounting for $2.9 \%(n=109)$ of HCV positive cases. No significant difference was observed among males and females in genotype distribution $(P>0.05)$. Our results are comparable with one of the largest sample sized study conducted in Pakistan. Attaullah $S$ et al,[19] reviewed 34 published papers (1996-2011) related to prevalence of HCV genotypes/serotypes and subgenotypes in Pakistan. HCV genotype/s distribution from all 34 studies was observed in $28,400 \mathrm{HCV}$ infected individuals in the following pattern: $1,999(7.03 \%)$ cases of genotype $1 ; 1,085$ $(3.81 \%)$ cases of genotype $2 ; 22,429(78.96 \%)$ cases of genotype $3 ; 453(1.59 \%)$ cases of genotype $4 ; 29$ $(0.10 \%)$ cases of genotype $5 ; 37(0.13 \%)$ cases of genotype $6 ; 1,429(5.03 \%)$ cases of mixed genotypes, and $939(3.30 \%)$ cases of untypeable genotypes. Genotype 3 occurred predominately in all the provinces of Pakistan. Second more frequently genotype was genotype 1 in Punjab province and untypeable genotypes in Sindh, Khyber Pakhtunkhwa and Balochistan provinces. The apparent differences from the current study $(78.9 \%$ vs $95.8 \%)$ may be explained by the changing trends over time. They reported data gathered till 2011 while we gathered data from 2010 to 2015 . The difference may also be attributed to the geographical difference. We published data exclusively of Rawalpindi/lslamabad region and they reviewed data of whole of the country. Inherent heterogeneity of data problems in such kinds of systematic review may also be attributed to the apparent differences in the results these two studies. However, the trends are generally similar. Hussain A et al,[20] reported the frequency distribution of HCV genotypes in a tertiary care centre of Karachi, the largest metropolitan city of Pakistan, where people of all ethnic origins are found. HCV genotyping was performed on a total of 457 patients who tested positive for presence of Hepatitis "C" viral RNA. The most prevalent genotype was type 3 with 392 (85.8\%) cases, followed by type 1 with $51(11.2 \%)$ cases. Our results are also comparable with other numerous studieswhere genotype 3 reported asremain the most prevalent subtype infecting people in Pakistan.[2135]

When we compare our results with global prevalence data we found them comparable with Messina JP et al,[36] who in their large meta analysis included 1,217 studies in our analysis, representing 117 countries and $90 \%$ of the global population. They found HCV genotype 1 is the most prevalent worldwide, comprising 83.4 million cases $(46.2 \%$ of all HCV cases), approximately one-third of which are in East Asia. Genotype 3 is the next most prevalent globally (54.3 million, 30.1\%); genotypes 2, 4 , and 6 are responsible for a total $22.8 \%$ of all cases; genotype 5 comprises the remaining $<1 \%$. While genotypes 1 and
3 dominate in most countries irrespective of economic status, the largest proportions of genotypes 4 and 5 are in lower-income countries. In another study by Petruzziello A et al,[37] who reviewed HCV prevalence and genotypes distribution worldwide reported HCV prevalence is estimated at 2.5\% (177.5 million of $\mathrm{HCV}$ infected adults), ranging from $2.9 \%$ in Africa and $1.3 \%$ in Americas, with a global viraemic rate of $67 \%$ (118.9 million of HCV RNA positive cases), varying from $64.4 \%$ in Asia to $74.8 \%$ in Australasia. HCV genotype 1 is the most prevalent worldwide (49.1\%), followed by genotype $3(17.9 \%), 4$ $(16.8 \%)$ and $2(11.0 \%)$. Genotypes 5 and 6 are responsible for the remaining $<5 \%$.

In summary, the most common type found in the region of Rawalpindi/lslamabad was genotype 3 over the study period. The results are comparable with other regions of Pakistanindicating that genotype 3 is the most prevalent genotype in the country. The good news is among all viral genotype 3 has shown to be a good responder to interferon therapy. HCV infection is becoming a public health issue in Pakistan and enormous efforts need to be done by public health authorities to educate the general population about the prevention and importance of early detection and start of curative therapy. The disease is generally affecting the poor masses and entails higher budget allocations for from the government for prevention and control. Centralized infectious diseases data registry system is needed which would pave the way towards effective control of the disease in Pakistan.

\section{Conclusion:}

The most common type found in the region of Rawalpindi/lslamabad was genotype 3 followed by genotype 1 as the second most common type. Our results are comparable with other regional and global studies. We recommend centralized infectious diseases data registry system which would pave the way towards effective control of this disease in Pakistan

\section{References}

1. Cooke GS, Lemoine M, Thursz M, Gore C, Swan $\mathrm{T}$, Kamarulzaman A et al. Viral hepatitis and the Global Burden of Disease: a need to regroup. J Viral Hepat. 2013;20:600-1.

2. Umer $M$, IqbalM.Hepatitis $C$ virus prevalence and genotype distribution in Pakistan: Comprehensive review of recent data. World $\mathrm{J}$ Gastroenterol.2016;22:1684-1700.

3. MohdHanafiah K, Groeger J, Flaxman AD, WiersmaST.Global epidemiology of hepatitis C virus infection: new estimates of age-specific antibody to HCV seroprevalence. Hepatology. 2013;57:1333-42.

4. Afridi S, Naeem M, Hussain A, Kakar N, Babar ME, Ahmad J. Prevalence of hepatitis C virus (HCV) genotypes in Balochistan. MolBiol Rep. 2009;36:1511-4. 
5. Idrees M, Riazuddin S. Frequency distribution of hepatitis $C$ virus genotypes in different geographical regions of Pakistan and their possible routes of transmission. BMC Infectious Diseases. 2008;8:69-72.

6. ZeinNN.Clinical Significance of Hepatitis C Virus Genotypes. ClinMicrobiol Rev. 2000;13:223-35.

7. Attaullah S, Khan S, Alil.Hepatitis C virus genotypes in Pakistan: a systemic review. Virol J. 2011;8:433-7.

8. Zein NN, Rakela J, Krawitt EL, Reddy KR, Tominaga T, Persing DH. Hepatitis $C$ virus genotypes in the United States: epidemiology, pathogenicity, and response to interferon therapy. Collaborative Study Group. Ann Intern Med. 1996;125:634-9.

9. Nousbaum JB, Pol S, Nalpas B, Landais P, Berthelot $P$, Brechot $C$. Hepatitis $C$ virus type $1 b$ (II) infection in France and Italy. Collaborative Study Group. Ann Intern Med. 1995;122:161-8.

10. Simmonds P. Genetic diversity and evolution of hepatitis C virus--15 years on. J Gen Virol. 2004;85:3173-88.

11. Ramia S, Eid-Fares J. Distribution of hepatitis C virus genotypes in the Middle East. Int $\mathrm{J}$ Infect Dis. 2006;10:272-7.

12. Messina JP, Humphreys I, Flaxman A, Brown A, Cooke GS, Pybus OG. Global Distribution and Prevalence of Hepatitis C Virus Genotypes.Hepatology. 2015;61:77-87.

13. Pawlotsky JM. Mechanisms of antiviral treatment efficacy and failure in chronic hepatitis C. Antiviral Res. 2003;59:1-11.

14. Idrees M, Rafique S, Rehman I, Akbar H, Yousaf $M Z$, Butt S. Hepatitis C virus genotype $3 a$ infection and hepatocellular carcinoma: Pakistan experience. World J Gastroenterol. 2009;15:5080-5.

15. Ansari N, Ahmed A, Esmail J. HCV Serotypes in Karachi. J Pak Med Assoc. 2002;52:219-20.

16. Zein NN.Clinical Significance of Hepatitis $C$ Virus Genotypes.ClinMicrobiol Rev. 2000;13:223-5.

17. Mujeeb SA. HCV 3 in Pakistan: Does it offer More Hope for Cure and Control. J Pak Med Assoc. 2002;52:191-2.

18. Umar M, Bilal M. Hepatitis C, A Mega Menace: A Pakistani Perspective. J Pioneer Med Sci. 2012;2:1-4.

19. Attaullah S, Khan S, Ali I. Hepatitis C virus genotypes in Pakistan: a systemic review. Virol J. 2011;8:433-6.

20. Hussain A, Nasir MI, Siddiqui AA, Ahmad A. Prevalence of hcv genotypes in patients reporting in tertiary health care hospital of Karachi. Pak J Pharmacol. 2011;28:23-9.

21. Umar M, Iqbal M. Hepatitis $C$ virus prevalence and genotype distribution in Pakistan: Comprehensive review of recent data. World $\mathrm{J}$
Gastroenterol. 2016;22:1684-700.

22. Shah HA, Jafri W, Matik 1 , et al. Hepatitis $C$ virus (HCV) genotypes and chronic liver disease in Pakistan. J. GastroenterolHepatol. 1997;11:75861.

23.Zuberi SJ, Arif A. Serotyping of Hepatitis C in Pakistan. J. Pak. Med. Assoc., 2002;52:218-19.

24. Ansari N, Ahmed A, Esmail J, et at. HCV Serotypes in Karachi, J. Pak. Med. Assoc., 2002;52:219-20

25. Riaz H, Latif MZ, Qureshi MA, Rouf A, Nizami R. HCV Prevalence and its Predominant Genotypes in Sargodha Region of Pakistan. Pak J Med Health Sci. 2016;10:6-10.

26. Husain A, Malik FA, Nagra H, Ehsan A, Ahmad Z, Abid M. Frequency of Different HCV Genotypes in Faisalabad. Ann Punj Med Coll. 2009;3:19-22.

27. Waqar M, Rehman $H$, Khan AU, Noor AA, Ali A, Wasim $M$, et al. Frequency Distribution of Hepatitis C Virus Genotypes in District Karachi, Pakistan. J Gastro Hepatol Res. 2014;3:1035-8.

28. Khan TM, Mehr MT, Ullah $H$, Khan $H$, Iman NU.Frequency of Hepatitis C VirusGenotypes in the North of Pakistan.Gomal J Med Sci. 2014;12:1-5.

29. Ali S, Ahmad A, Khan RS, Khan S, Hamayun M, Khan SA, et al. Genotyping of HCV RNA Reveals That $3 a$ Is the Most Prevalent Genotype in Mardan, Pakistan. AdvVirol. 2014;2014:1-5.

30. Khan N, Akmal M, Hayat M, Umar M, Ullah A, Ahmed I, et al. Geographic Distribution of Hepatitis C Virus Genotypes in Pakistan. Hepat Mon. 2014;14:e20299.

31. Tahir M, Suhail AM, Tahir F, Hamza SA, Bukhari $\mathrm{SAH}$. Detection and genotyping of hcv in patients of sheikh zayed hospital, lahore, Pakistan. JUMDC. 2016;7;25-30.

32. Afridi S, Naeem M, Hussain A, Kakar N, Babar ME, Ahmad J. Prevalence of hepatitis C virus (HCV) genotypes in Balochistan. MolBiol Rep. 2009;36:1511-4.

33. Mahmood K, Mohammad N, Abidullah. Genotype variation of hepatitis $C$ virus in district Buner Swat. J Ayub Med Coll. 2011;23:18-21.

34. Rasheed A, Ullah S, Naeem S, Zubair M, Ahmad W, Hussain Z. Occurrence of HCV genotypes in different age groups of patients from Lahore, Pakistan. Adv life sci. 2014;1:89-95.

35. Saleha S, Kamal A, Ullah F, Khan N, Mahmood A, Khan S. Prevalence of Hepatitis C Virus Genotypes in District Bannu, Khyber Pakhtunkhwa, Pakistan. Hepat Res Treat. 2014;2014:1-5.

36. Messina JP, Humphreys I, Flaxman A, Brown A, Cooke GS, Pybus OG, et al. Global Distribution and Prevalence of Hepatitis C Virus Genotypes. Hepatol. 2015;61:77-87.

37. Petruzziello A, Marigliano S, Loquercio G, 
Cozzolino A, Cacciapuoti C. Global epidemiology of hepatitis $C$ virus infection: An up-date of the distribution and circulation of hepatitis $C$ virus genotypes. World J Gastroenterol. 2016; $22: 7824-40$. 